\title{
Making Simple Repairs: Building Your Toolbox ${ }^{1}$
}

Mary N. Harrison ${ }^{2}$

Every home needs some basic tools for use in simple maintenance.

- Keep all of your tools in your toolbox. That way you can always find your tools when you need them. A simple metal box is fine.

- Always put your tools back in the box after using them.

\section{Important Tools To Have}

- A medium weight (12-13 ounces) claw hammer.

- Two screwdrivers. There are two types of screwdrivers. Buy one of each type.

- A straight blade (flat head).

- A Phillips head. (X-head)

The screwdrivers must fit into the head of the screw, so they come in several sizes.
It is easier to put a screw into wood if you make a hole first. Pound a nail a little way into the wood. Remove the nail and put the screw in the hole made by the nail.

- A pair of slip-joint pliers. They can be used for many jobs around the house. Use pliers to hold a nut while you turn a bolt with a screwdriver.

- Pliers can be used to bend or remove a nail or brad. A claw hammer can also be used to pull nails. Pliers can be used to cut wire or straighten a bent nail and to tighten or loosen a bolt.

- An adjustable wrench. This tool can be adjusted to several sizes. It can be used to loosen or tighten nuts.

- A small can of penetrating oil. The oil can be used to lubricate nuts, bolts and for many other purposes.

- A package of mix sized nails and a package of mixed size screws.

- A box of mixed-size wood screws, metal screws,

1. This document is FCS5234-01, one of a series of the Department of Family, Youth and Community Sciences, Florida Cooperative Extension Service, Institute of Food and Agriculture Sciences, University of Florida. Publication: May 2002. Revised: December 2005. Please visit the EDIS Web site at http://edis.ifas.ufl.edu.

2. Mary N. Harrison, professor, Department of Family, Youth and Community Sciences, Cooperative Extension Service, Institute of Food and Agricultural Sciences, University of Florida, Gainesville, 32611.

The Institute of Food and Agricultural Sciences (IFAS) is an Equal Opportunity Institution authorized to provide research, educational information and other services only to individuals and institutions that function with non-discrimination with respect to race, creed, color, religion, age, disability, sex, sexual orientation, marital status, national origin, political opinions or affiliations. U.S. Department of Agriculture, Cooperative Extension Service, University of Florida, IFAS, Florida A. \& M. University Cooperative Extension Program, and Boards of County Commissioners Cooperating. Larry Arrington, Dean 
- A package of mixed-size nuts and bolts.

- A box of mixed-size nails.

\section{Picture Hanging}

Pounding a nail into a wall to hang a picture or mirror can damage the wall. An inexpensive picture hanging kit makes it easy to hang a picture without damage to the wall. It will also hold your picture more securely. There are two kinds of picture hangers.

- One kind of picture/mirror hanger has a metal hanger and uses a small nail to hold the hanger in place. This type will support the most weight.

- The other type of picture/mirror hanger uses a sturdy fabric tab that is glued to the wall. A hanger is at the bottom of the fabric tab.

Generally, pictures are hung at eye level. 